\title{
The prognostic value of cyclooxygenase-2 expression in patients with esophageal cancer: evidence from a meta-analysis
}

This article was published in the following Dove Press journal:

OncoTargets and Therapy

9 June 2017

Number of times this article has been viewed

\author{
Zaoxiu $\mathrm{Hu}^{1, *}$ \\ Yanlong Yang $2, *$ \\ Yonghe Zhao ${ }^{3}$ \\ Yunchao Huang ${ }^{2,4}$ \\ 'Department of Pathology, \\ ${ }^{2}$ Department of Thoracic Surgery I, \\ The Third Affiliated Hospital of \\ Kunming Medical University (Yunnan \\ Cancer Hospital), ${ }^{3}$ Department of \\ Pathology, The Forensic School of \\ Kunming Medical University, ${ }^{4}$ Cancer \\ Research Institute of Yunnan Province, \\ The Third Affiliated Hospital of \\ Kunming Medical University (Yunnan \\ Cancer Hospital), Kunming, Yunnan \\ Province, People's Republic of China \\ *These authors contributed equally \\ to this work
}

Correspondence: Yunchao Huang

No 519 Kunzhou Road, Xishan District, Kunming 650I 18, Yunnan Province,

People's Republic of China

Tel +868718185656

Email hycyn2008@।63.com
Abstract: Published studies have investigated the prognostic role of cyclooxygenase-2 (COX-2) expression in patients with esophageal cancer (EC), but the result remains controversial. Thus, this meta-analysis was conducted to comprehensively evaluate the impact of COX-2 expression on the prognostic value in patients with EC. Relevant studies were identified from PubMed, EMBASE, and Web of Science databases. Studies that detected the COX-2 expression by immunohistochemistry and evaluated the relationship between COX-2 expression and overall survival (OS) or clinicopathological parameters were used in our analysis. The summary hazard ratios (HRs) or odds ratios were calculated to assess the risk or hazard association. A total of 25 studies, which included 2,465 patients, were included in our meta-analysis. Our analysis suggested that overexpression of COX-2 was associated with poor OS (HR $=1.60$, $95 \% \mathrm{CI}=1.32-1.94, P<0.001)$. Subgroup analyses by race, percentage of high/positive COX-2 expression, histology type, treatment, and sample size all suggested significant association. Moreover, overexpression of COX-2 was significantly associated with depth of invasion, lymph node metastasis, distant metastasis, and TNM stage. This meta-analysis suggested that overexpression of COX-2 might serve as a prognostic biomarker for EC. Large well-designed prospective studies are needed to confirm our conclusion.

Keywords: esophageal cancer, cyclooxygenase-2, prognosis, meta-analysis

\section{Introduction}

Esophageal cancer (EC) ranks as the eighth most common cancer and the sixth most common cause of death from cancer worldwide. ${ }^{1} \mathrm{EC}$ can be classified as esophageal squamous cell carcinoma (ESCC) and esophageal adenocarcinoma (EADC). ${ }^{1,2}$ Over the past few decades, although significant advances have been made in surgical techniques, radiotherapy and chemotherapy, the prognosis of EC remains unsatisfactory. The overall 5-year survival rate of EC ranges from $15 \%$ to $25 \%$. Poor outcomes in patients with EC are related to diagnosis at advanced (metastatic) stages and the propensity for metastases, even when tumors are superficial. ${ }^{3}$

Cyclooxygenases (COXs) are rate-limiting enzymes that catalyze the conversion of arachidonic acid into prostaglandin. Two distinct forms of COX have been recognized: COX-1 and COX-2. COX-1 is constitutively expressed in a wide variety of cells and tissues and is responsible for the production of prostaglandins that are important for maintaining homeostasis. In contrast, $\mathrm{COX}-2$ is normally absent, and its expression is induced by different mediators of inflammation, such as interleukin-1, tumor necrosis factor-1, and lipopolysaccharide. COX-2 is mostly expressed in pathological states, principally in inflammatory reactions and in oncogenesis. ${ }^{4}$ Preclinical studies have 
shown that COX-2 is widely involved in carcinogenesis, including cell proliferation, apoptosis inhibition, angiogenesis, invasiveness, and immunosuppression. ${ }^{5}$ On the basis of the evidence, a series of clinical studies have evaluated the prognostic role of COX-2 in patients with EC. Many studies suggested that the overexpression of COX-2 was associated with poor prognosis. ${ }^{6-14}$ However, other findings did not support this view; ${ }^{15-21}$ some studies even found the trend that the overexpression of COX-2 was related to favorable prognosis, although the association did not reach the significant level. ${ }^{8,22-24}$ Considering the small sample size and the limited static power in individual study, a meta-analysis was necessary to comprehensively evaluate the prognostic significance of COX-2 expression in patients with EC.

\section{Materials and methods}

\section{Literature search}

A comprehensive literature search was conducted in the databases of PubMed, EMBASE, and Web of Science. The end search limit was December 31, 2016. The following search terms were used to identify the studies: ("cyclooxygenase-2" or "cyclooxygenase" or "COX-2") and ("esophageal cancer" or "esophageal carcinoma" or "esophageal neoplasms" or "esophageal squamous cell carcinoma" or "ESCC" or "esophageal adenocarcinoma" or "EADC"). Furthermore, references of retrieved articles and reviews were manually screened for additional studies.

\section{Inclusion and exclusion criteria}

The inclusion criteria were used to identify the eligible studies: 1) human-based investigations; 2) pathologically confirmed EC; 3 ) articles with full texts published in English; 4) detecting COX-2 expression in the primary tumor tissues by immunohistochemistry (IHC) assay; 5) evaluating the correlation between COX-2 expression and OS, or clinicopathological parameters such as histological grade, depth of invasion, lymph-node metastasis, distant metastasis, and TNM stage; 6) providing sufficient information to estimate hazard ratio (HR) or odds ratio (OR) and their 95\% confidence intervals (CIs). The exclusion criteria were as follows: 1) studies published in non-English; 2) cell line and animal studies, case reports, letters, reviews, or meta-analyses; 3) studies in which necessary data to extract the relationship between COX-2 expression and OS or clinicopathological parameters were not provided; 4) for overlapped studies, the studies with the small sample size and the insufficient data set were excluded.

\section{Data extraction}

Two investigators (YLY and ZXH) independently reviewed the eligible studies and extracted the following data: surname of the first author, publication year, country, ethnicity, sample size, disease stage, histology type, assay method, cutoff value, percentage of high/positive COX-2 expression, and the outcomes. All data were then examined by two investigators independently (YLY and ZXH). Disagreements were resolved by discussion among all authors.

\section{Statistical analysis}

The impact of COX-2 expression on overall survival (OS) was measured by the combined HRs and their 95\% CIs extracted from each eligible study. The HR and its 95\% CI in each eligible study were directly extracted from report or indirectly estimated by methods described by Tierney et al. ${ }^{25}$ For the relationship between COX-2 expression and clinicopathological parameters, ORs and their 95\% CIs were combined to estimate the effective value. The overall $\mathrm{HR} / \mathrm{OR}$ and its 95\% CI greater than 1 were considered statistically significant and indicated a worse effect for the group with high/positive COX-2 expression. Heterogeneity between studies was detected by the Q-test and the $I^{2}$ metric (no heterogeneity: $I^{2}=0 \%-25 \%$; moderate heterogeneity: 25\%-50\%; large heterogeneity: 50\%-75\%; and extreme heterogeneity: $75 \%-100 \%) .{ }^{26}$ If $P \geq 0.10$ in the Q-test or $I^{2}<50 \%$, the fixed-effects model (the Mantel-Haenszel method) was used. ${ }^{27}$ Otherwise, the random-effects model (the DerSimonian-Laird method) was used. ${ }^{28}$ Subgroup analyses by different analytical methods (race, percentage of high COX-2, histological type, treatment, and sample size) were performed in the analysis of OS. In addition, publication bias was assessed by the methods reported by Begg and Mazumdar ${ }^{29}$ and Egger et al. ${ }^{30}$ Funnel plots were also applied for the assessment of possible publication biases. All $P$-values were two-tailed, and the $P<0.05$ was considered statistically significant. Most of the statistical analyses in this study were conducted by the STATA software (version 11.2; StataCorp., College Station, TX, USA).

\section{Results}

\section{Eligible studies}

A total of 399 studies were yielded by the systematic literature search. After screening of titles and abstracts, 345 irrelevant studies were excluded and the remaining 54 studies were further evaluated for potentially eligible studies. After carefully reading the full text, 29 studies were excluded for 
the following reasons: not an IHC method $(n=3)$, cell-line or animal experiments $(n=7)$, without outcome of interest $(n=6)$, reviews and meta-analyses ( $n=5)$, and insufficient data $(n=8)$. As a result, 25 studies, which included 2,465 EC patients, were included in our analysis ${ }^{6-24,31-36}$ (Figure 1).

The general characteristics of 25 studies were summarized in Table 1. Four studies evaluated only clinicopathological parameters, ${ }^{8,24,31,33} 5$ studies evaluated only OS, $, 11,18,20,21$ and the remaining 16 studies investigated both clinicopathological parameters and OS. 6,7,9,10,12-17,19,22,23,32-36 Eighteen studies were conducted on Asian patients, ${ }^{6,9-13}$ 16,18,19,21-24,31,33-36 and 7 studies were conducted on Caucasian patients. ${ }^{7,8,14,15,17,20,32}$ The percentage of high/positive COX-2 expression was $>50 \%$ in 15 studies, , $^{6,10,11,13-19,21,22,31,34,36}$ and the remaining 10 studies shared the percentage of high/positive COX-2 expression $<50 \%$. $^{7,9,12,20,21,23,24,32,33}$ Among these studies, ESCC was investigated in 17 studies, ${ }^{6,9-13,16,18,19,21-24}$ 31-34,36 EADC was investigated in 5 studies, ${ }^{7,8,14,17}$ and another 3 studies evaluated both histological types. ${ }^{15,20,21}$ The patients in 17 studies were treated by surgery only; ${ }^{7-11,13-15}$, $17,19,21,22,24,31,33,34$ the surgery plus additional chemotherapy or radiotherapy was applied in 8 studies. , $^{6,12,16,18,20,23,32,36}$

\section{Impact of COX-2 expression on OS of EC}

Twenty-four studies, which included 2,270 patients, reported the relationship between COX-2 expression and OS. ${ }^{12-15,17-22,24,26-36}$ The pooled HR was 1.60 (95\% CI: $1.32-1.94, P<0.001)$ with moderate heterogeneity $\left(I^{2}=49.1 \%\right.$,

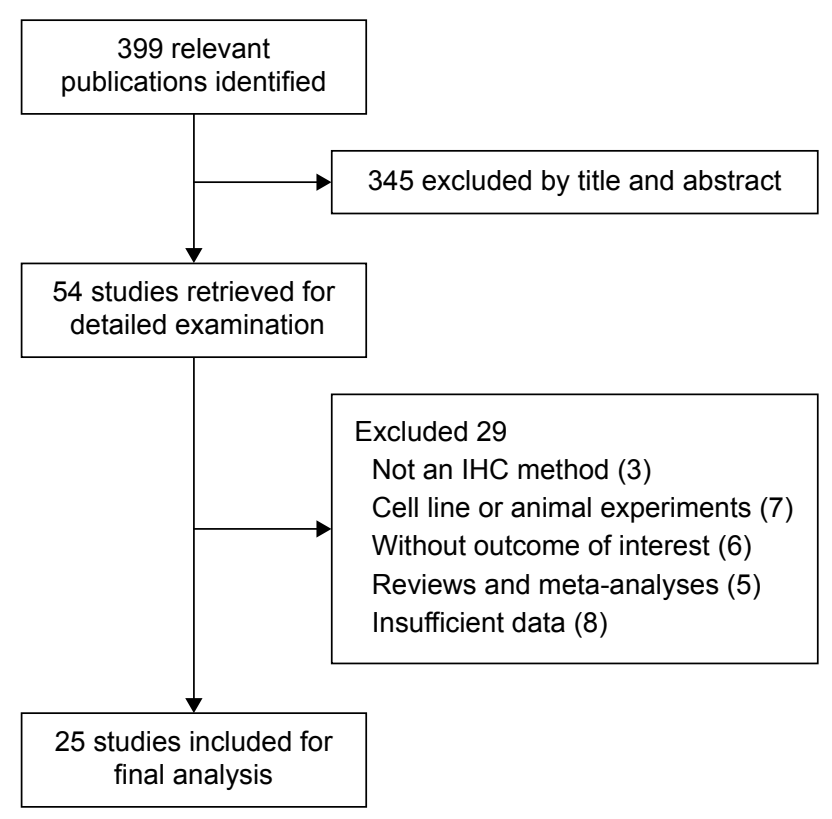

Figure I Flow diagram of studies selection procedure. Abbreviation: IHC, immunohistochemistry.
$P=0.004)$, indicating that the EC patients with overexpression of COX-2 would have worse OS (Table 2 and Figure 2).

Further subgroup analysis by race was done; the analysis suggested that overexpression of COX-2 was related to worse OS in both Asian and Caucasian patients (Asian: $\mathrm{HR}=1.49,95 \% \mathrm{CI}=1.20-21.85, P<0.001, I^{2}=50.0 \%$, $P=0.012$; Caucasian: $\mathrm{HR}=2.04,95 \% \mathrm{CI}=1.54-2.71$, $\left.P<0.001, I^{2}=35.5 \%, P=0.145\right)$. When we conducted subgroup analysis by the percentage of high/positive COX-2 expression, we found that both studies with high/positive COX- 2 expression $\geq 50 \%$ and $<50 \%$ showed the significant association (high/positive COX-2 $\geq 50 \%$ : HR $=1.55$, 95\% CI $=1.35-1.78, P<0.001, I^{2}=40.4 \%, P=0.064$; low $/$ negative $\mathrm{COX}-2<50 \%$ : $\mathrm{HR}=1.53,95 \% \mathrm{CI}=1.02-2.29$, $\left.P=0.038, I^{2}=60.1 \%, P=0.005\right)$. When histology type was taken into consideration, high/positive COX-2 expression still had impact on OS in both ESCC and EADC patients (ESCC: $\mathrm{HR}=1.46,95 \% \mathrm{CI}=1.17-1.83, P=0.001$, $I^{2}=52.0 \%, P=0.007$; EADC $: \mathrm{HR}=2.13,95 \% \mathrm{CI}=1.62-2.79$, $\left.P<0.001, I^{2}=26.4 \%, P=0.246\right)$. When we focus on treatment strategy, for studies that received surgery only, the HR was $1.52\left(95 \% \mathrm{CI}=1.21-1.92, P<0.001, I^{2}=52.6 \%\right.$, $P=0.006$ ); for studies that received surgery plus additional chemoradiotherapy, the pooled HR was $1.72(95 \%$ $\left.\mathrm{CI}=1.23-2.32, P=0.004, I^{2}=53.7 \%, P=0.056\right)$. Subgroup analysis by sample size $(\geq 100$ and $<100)$ also suggested the significant prognostic impact of high/positive COX-2 expression (Table 2).

\section{COX-2 expression and clinicopathological parameters in patients with EC}

The relationship between the COX-2 expression and the following clinicopathological parameters was collected for analysis: histological grade, ${ }^{6,7,9,10,13,14,19,22-}$ 24,31-36 depth of invasion, 6,7,9,10,12-15,17,19,22-24,31,32,34,36 lymph-node metastasis, $, 6,7,9,10,12-15,17,19,22-24,31,32,34,36$ distant metastasis, ${ }^{6,7,10,14,22,23,32}$ and TNM stage. .7, $, 9,10,12-14,16,22-24,32,33,35,36^{-10}$ Our analysis suggested that high/positive COX-2 expression was significantly associated with the depth of invasion $\left(\mathrm{T}_{3 / 4}\right.$ vs $_{1 / 2}: \mathrm{OR}=2.36,95 \% \mathrm{CI}=1.61-63.46, P<0.001, I^{2}=57.8 \%$, $P=0.002$; Figure 3A), distant metastasis (yes vs no: $\mathrm{OR}=1.41$, $95 \% \mathrm{CI}=1.02-1.95, P=0.037, I^{2}=41.1 \%, P=0.117$; Figure $3 \mathrm{~B}$ ), and TNM stage (III/IV vs I/II: $\mathrm{OR}=1.84,95 \% \mathrm{CI}=1.23-2.75$, $P=0.003, I^{2}=67.1 \%, P<0.001$; Figure $3 \mathrm{C}$ ). However, no significant association was found in the relationship between COX-2 expression and histological grade and lymph-node metastasis (Table 2). 


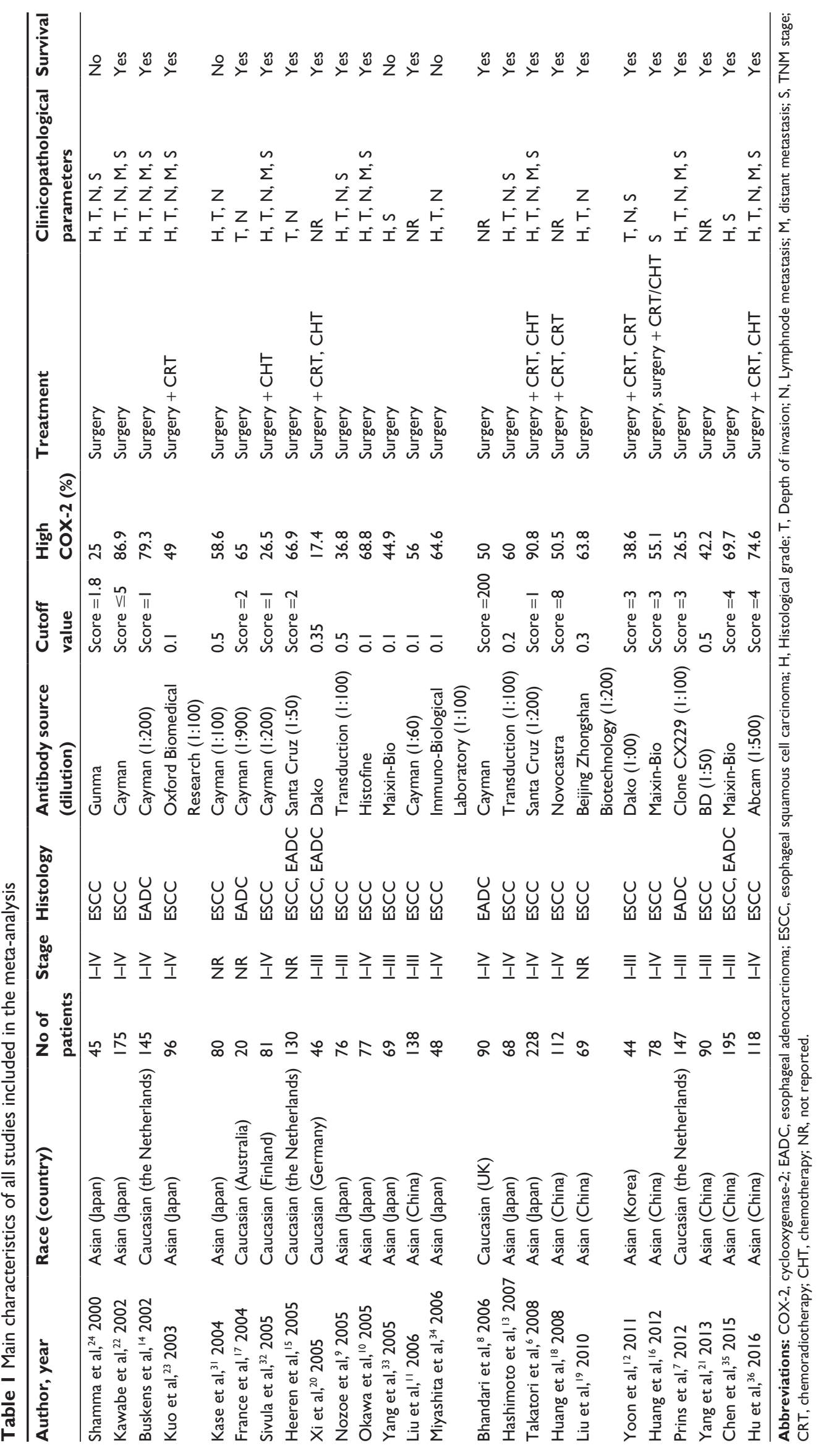


Table 2 Main meta-analysis results of COX-2 expression in patients with esophageal cancer

\begin{tabular}{|c|c|c|c|c|c|c|c|c|}
\hline \multirow[t]{2}{*}{ Analysis } & \multirow{2}{*}{$\begin{array}{l}\text { Number of } \\
\text { studies (number } \\
\text { of patients) }\end{array}$} & \multirow[t]{2}{*}{ HR (95\% Cl) } & \multirow[t]{2}{*}{$P$-value } & \multirow[t]{2}{*}{ Model } & \multicolumn{2}{|c|}{ Heterogeneity } & \multicolumn{2}{|c|}{ Publication bias } \\
\hline & & & & & $P^{2}$ & Phet & Begg's P & Egger's $P$ \\
\hline Overall survival & $24(2,278)$ & $1.60(1.32-1.94)$ & $<0.001$ & $\mathrm{R}$ & 49.1 & 0.004 & 1.00 & 0.63 \\
\hline \multicolumn{9}{|l|}{ Subgroup I: race } \\
\hline Asian & $16(1,609)$ & $\mathrm{I} .49(1.20-21.85)$ & $<0.001$ & $\mathrm{R}$ & 50.0 & 0.012 & 0.50 & 0.74 \\
\hline Caucasian & $8(669)$ & $2.04(I .54-2.7 I)$ & $<0.001$ & $\mathrm{~F}$ & 35.5 & 0.145 & 0.87 & 0.39 \\
\hline \multicolumn{9}{|c|}{ Subgroup 2: percentage of high/positive COX-2 expression } \\
\hline$<50$ & II (824) & $1.53(1.02-2.29)$ & 0.038 & $\mathrm{R}$ & 60.1 & 0.005 & 0.16 & 0.83 \\
\hline$\geq 50$ & $13(1,454)$ & $1.55(1.35-1.78)$ & $<0.001$ & $\mathrm{R}$ & 40.4 & 0.064 & 0.06 & 0.42 \\
\hline \multicolumn{9}{|l|}{ Subgroup 3: histology type } \\
\hline ESCC & $17(1,5 \mid 5)$ & $1.46(1.17-1.83)$ & 0.001 & $\mathrm{R}$ & 52 & 0.007 & 0.45 & 0.83 \\
\hline EADC & $5(522)$ & $2.13(1.62-2.79)$ & $<0.001$ & $\mathrm{~F}$ & 26.4 & 0.246 & 1 & 0.892 \\
\hline \multicolumn{9}{|l|}{ Subgroup 4: treatment } \\
\hline Surgery & $17(1,634)$ & $1.52(1.21-1.92)$ & $<0.001$ & $\mathrm{R}$ & 52.6 & 0.006 & 0.54 & 0.99 \\
\hline Surgery + chemoradiotherapy & $6(553)$ & $1.72(1.23-2.32)$ & 0.004 & $\mathrm{R}$ & 53.7 & 0.056 & 0.85 & 0.29 \\
\hline Chemoradiotherapy & $\mathrm{I}(91)$ & I.7I (0.82-2.63) & 0.192 & & & & & \\
\hline \multicolumn{9}{|l|}{ Subgroup 5: sample size } \\
\hline$\geq 100$ & $9(1,356)$ & $1.75(1.43,2.14)$ & $<0.001$ & $\mathrm{R}$ & 65.9 & 0.003 & 1.00 & 0.59 \\
\hline$<100$ & $15(922)$ & $1.46(1.26,1.69)$ & $<0.001$ & $\mathrm{~F}$ & 29 & 0.139 & 0.921 & 0.96 \\
\hline Clinicopathological parameters & & OR $(95 \% \mathrm{Cl})$ & & & & & & \\
\hline $\begin{array}{l}\text { Histological grade (poor vs well/ } \\
\text { moderate) }\end{array}$ & $18(1,959)$ & $1.28(0.90,1.82)$ & 0.169 & $\mathrm{R}$ & 56.2 & 0.002 & 0.68 & 0.83 \\
\hline Depth of invasion (T3/4 vs TI/2) & $17(1,684)$ & $2.36(1.61,3.46)$ & $<0.001$ & $\mathrm{R}$ & 57.8 & 0.002 & 0.16 & 0.12 \\
\hline Lymph-node metastasis (yes vs no) & $18(1,749)$ & $1.33(0.93,1.91)$ & 0.121 & $\mathrm{R}$ & 61.5 & $<0.00$ I & 0.62 & 0.48 \\
\hline Distant metastasis (yes vs no) & $7(963)$ & $1.41(1.02,1.95)$ & 0.037 & $\mathrm{~F}$ & 41.1 & 0.117 & 0.035 & 0.17 \\
\hline Stage (III/IV vs I/II) & $15(1,622)$ & $1.84(1.23,2.75)$ & 0.003 & $\mathrm{R}$ & 67.1 & $<0.001$ & 0.067 & 0.19 \\
\hline
\end{tabular}

Abbreviations: $\mathrm{Cl}$, confidence interval; COX-2, cyclooxygenase-2; EADC, esophageal adenocarcinoma; ESCC, esophageal squamous cell carcinoma; HR, hazard ratio; OR, odds ratio; $F$, fixed-effect model; $R$, random effect model; Phet, $P$ for heterogeneity.

\begin{tabular}{|c|c|c|c|}
\hline Study ID & & HR $(95 \% \mathrm{Cl})$ & $\%$ weight \\
\hline Shamma et al ${ }^{24}$ & $\sigma^{\prime}$ & $0.44(0.13-1.54)$ & 1.96 \\
\hline Kawabe et $\mathrm{al}^{22}$ & & $0.66(0.40-1.09)$ & 6.07 \\
\hline Buskens et al ${ }^{14}$ & & $3.50(1.60-7.90)$ & 3.71 \\
\hline Kuo et $\mathrm{al}^{23}$ & & $0.79(0.45-1.37)$ & 5.54 \\
\hline France et al ${ }^{17}$ & & $1.09(0.23-5.10)$ & 1.34 \\
\hline Sivula et $\mathrm{al}^{32}$ & & $0.73(0.32-1.64)$ & 3.60 \\
\hline Heeren et $\mathrm{al}^{15}$ & & $2.23(0.75-6.58)$ & 2.40 \\
\hline Nozoe et $\mathrm{al}^{9}$ & & $3.82(1.27-11.48)$ & 2.35 \\
\hline Okawa et $a^{10}$ & $\rightarrow$ & $1.77(1.19-2.64)$ & 7.17 \\
\hline Xi et $\mathrm{al}^{20}$ & & $1.97(0.67-5.83)$ & 2.42 \\
\hline Bhandari et $\mathrm{al}^{8}$ & & $2.91(1.78-4.76)$ & 6.17 \\
\hline Heeren et al ${ }^{15}$ & & $1.73(0.96-3.13)$ & 5.23 \\
\hline Liu et al ${ }^{11}$ & & $1.66(1.07-2.56)$ & 6.75 \\
\hline Hashimoto et $\mathrm{l}^{13}$ & ح & $1.45(1.17-1.78)$ & 9.22 \\
\hline Takatori et al $^{6}$ & & $2.50(1.10-5.79)$ & 3.53 \\
\hline Huang et al ${ }^{18}$ & & $1.71(0.82-2.63)$ & 5.33 \\
\hline Huang et $\mathrm{al}^{18}$ & & $2.81(0.93-8.46)$ & 2.34 \\
\hline Liu et al $^{19}$ & & $1.34(0.38-4.81)$ & 1.88 \\
\hline Yoon et al ${ }^{12}$ & & $2.34(1.11-4.91)$ & 4.06 \\
\hline Prins et $\mathrm{al}^{7}$ & & $1.64(1.04-32.61)$ & 1.11 \\
\hline Huang et al ${ }^{16}$ & & $1.11(0.53-2.32)$ & 4.07 \\
\hline Yang et $\mathrm{al}^{21}$ & & $1.64(0.76-3.51)$ & 3.92 \\
\hline Chen et $\mathrm{al}^{35}$ & $a$ & $1.47(0.74-2.92)$ & 4.47 \\
\hline Hu et $\mathrm{al}^{36}$ & & $2.32(1.30-4.12)$ & 5.37 \\
\hline Overall $\left(I^{2}=49.1 \%, P=0.004\right)$ & $\hat{1}$ & $1.60(1.32-1.94)$ & 100 \\
\hline
\end{tabular}

Figure 2 Funnel plot of the association of COX-2 expression with overall survival (OS) in patients with esophageal cancer.

Note: Weights are from random effects analysis.

Abbreviations: $\mathrm{Cl}$, confidence interval; COX-2, cyclooxygenase-2; HR, hazard ratio. 


\section{Publication bias}

The assessment of publication bias showed that the Egger's tests were not significant $(P>0.05)$ for studies included in the analysis of OS and clinicopathological parameters. When Begg's tests were applied to detect publication bias, except for distant metastasis $(P=0.035)$, no additional publication bias was found in other comparisons (Table 2).

\section{Discussion}

In this meta-analysis, we explored the relationship between COX-2 expression and the prognosis in patients with EC. We analyzed 2,465 patients from 25 studies and demonstrated that overexpression of COX-2 might be associated with poor OS. In addition, we found that overexpression of COX-2 was related to the depth of invasion, distant metastasis, and TNM stage; however, no association was found in histological grade and lymph-node metastasis.

The relationship between COX-2 and other cancer was also investigated by other meta-analyses. Peng et $\mathrm{al}^{37}$ found that COX-2 $765 \mathrm{G}>\mathrm{C}$ polymorphism was associated with colorectal cancer risk. Another study by Wang et $\mathrm{al}^{38}$ found that COX-2 overexpression was associated with poor prognosis and cancer progression. COX $-2765 \mathrm{G}>\mathrm{C}$ is a functional polymorphism located at $765 \mathrm{bp}$ upstream $(2,765 \mathrm{bp})$ from the transcription starting site. It changes a putative stimulatory protein (Sp1)-binding site in the promoter of COX-2 between 2,766 and 2,761 bp, but it creates an E2 promoter factor
A

Study ID

Shamma et $\mathrm{al}^{24}$

Buskens et al $^{14}$

Kawabe et $\mathrm{al}^{22}$

Kuo et $\mathrm{al}^{23}$

Kase et $\mathbf{a l}^{31}$

France et $\mathrm{al}^{17}$

Sivula et $\mathrm{al}^{32}$

Heeren et al ${ }^{15}$

Nozoe et $a^{9}$

Okawa et $\mathrm{al}^{10}$

Miyashita et al ${ }^{34}$

Hashimoto et $\mathrm{al}^{13}$

Takatori et $\mathrm{al}^{6}$

Liu et al ${ }^{19}$

Yoon et al ${ }^{12}$

Prins et $\mathrm{al}^{7}$

Hu et al ${ }^{36}$

Overall $\left(I^{2}=57.8 \%, P=0.002\right)$

Depth of invasion (T3+T4 vs T1+T2)

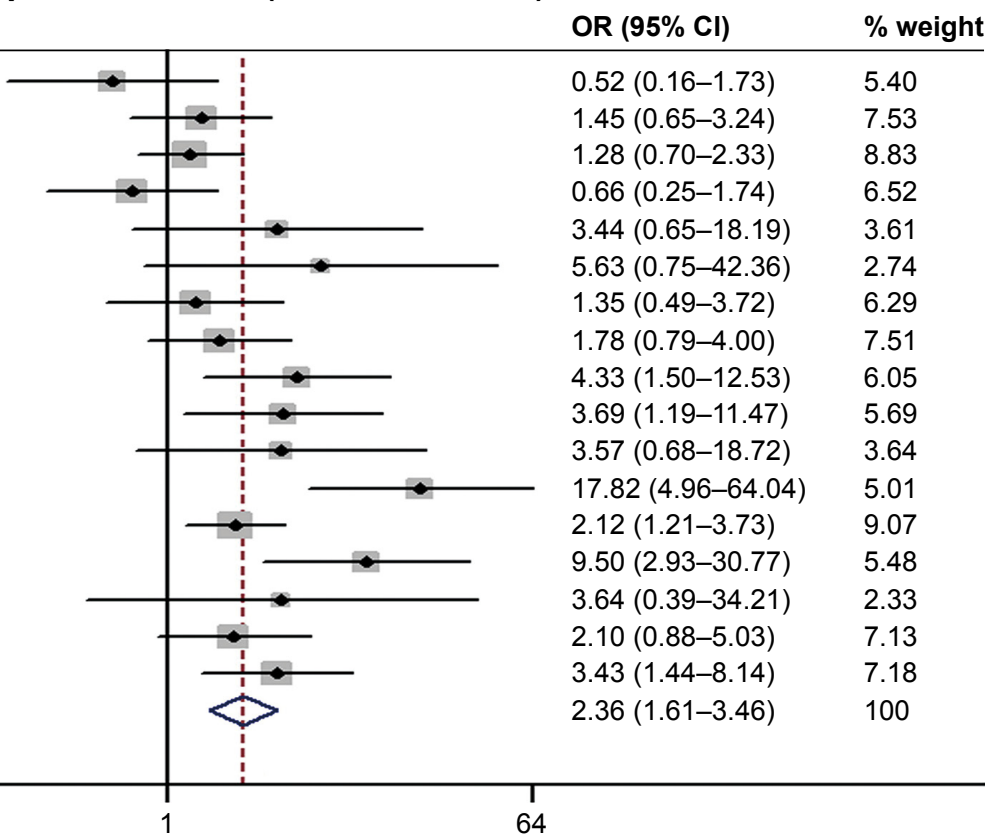

B

Distant metastasis (yes vs no)

\begin{tabular}{|c|c|c|}
\hline Study ID & OR $(95 \% \mathrm{Cl})$ & $\%$ weight \\
\hline Buskens et $\mathrm{al}^{14}$ & $1.71(0.55-5.39)$ & 7.98 \\
\hline Kawabe et $\mathrm{al}^{22}$ & $1.88(0.86-4.13)$ & 15.18 \\
\hline Kuo et $\mathrm{al}^{23}$ & $0.33(0.12-0.95)$ & 20.35 \\
\hline Sivula et $\mathrm{al}^{32}$ & $1.05(0.37-2.98)$ & 10.86 \\
\hline Okawa et $\mathrm{al}^{10}$ & $0.86(0.20-3.68)$ & 6.07 \\
\hline Takatori et al ${ }^{6}$ & $1.92(1.07-3.44)$ & 26.60 \\
\hline Prins et $\mathrm{al}^{7}$ & $1.88(0.81-4.39)$ & 12.96 \\
\hline Overall $\left(I^{2}=41.1 \%, P=0.117\right)$ & $1.41(1.02-1.95)$ & 100 \\
\hline
\end{tabular}

Figure 3 (Continued) 
C

Study ID

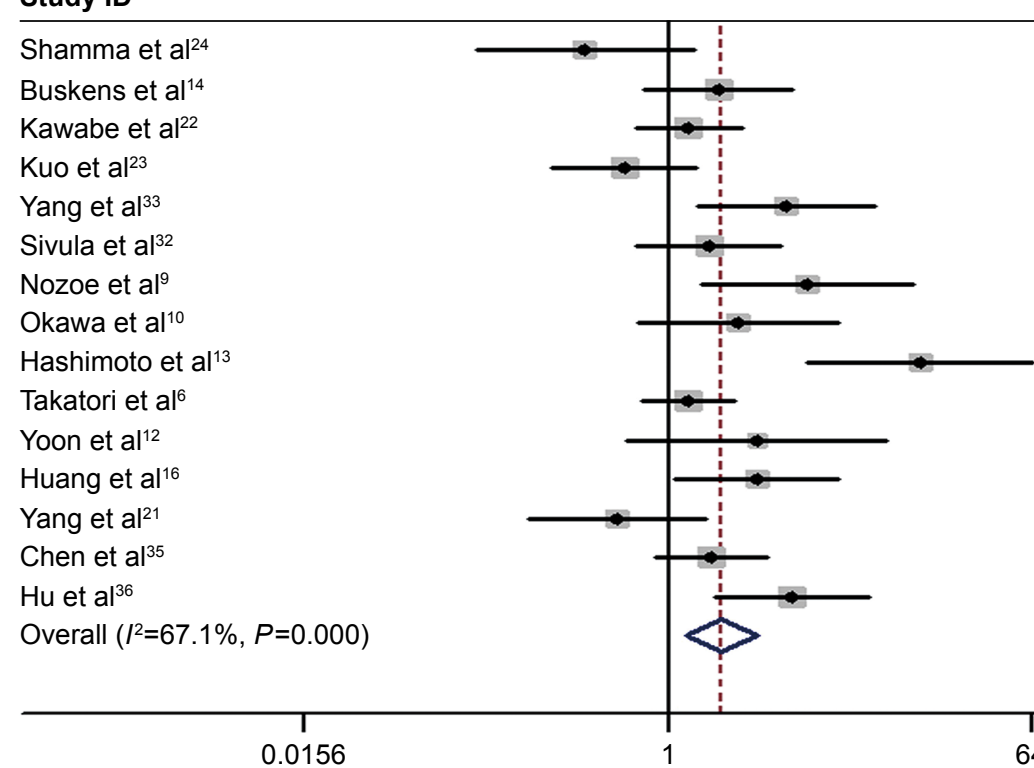

Figure 3 Funnel plot of the association of COX-2 expression with the depth of invasion (T) (A), distant metastasis (M) (B), and TNM stage (C) in patients with esophageal cancer.

Note: Weights are from random-effects analysis.

Abbreviations: $\mathrm{Cl}$, confidence interval; COX-2, cyclooxygenase-2; OR, odds ratio.

(E2F) binding site, leading to high transcription activity and increased COX-2 expressions, which might be involved in the development of cancers. All this evidence suggested that COX-2 plays an important role in cancer development and progression.

The results of our study also provided the evidence that the use of a COX-2 inhibitor could be an effective therapeutic strategy for patients with EC. COX-2 is considered to be a novel target for cancer prevention and therapy. As COX-2 may contribute to tumorigenesis, some nonsteroidal antiinflammatory drugs such as aspirin and coxibs were introduced in clinical trials, initially for chemoprevention and later for cancer therapy. ${ }^{5,39}$ Clinical studies were designed to evaluate the efficacy of celecoxib in combination with adjuvant systemic chemotherapeutic or radiation therapy in various cancers, such as nonsmall cell lung cancer, prostate cancer, breast cancer, and colorectal cancer; however, the inconclusive results have generated. ${ }^{5,40-43}$ Recently, a Phase 2 clinical trial (NCT00137852) evaluated the safety and efficacy of combining celecoxib with neoadjuvant irinotecan/cisplatin chemoradiation. They found that the addition of celecoxib to neoadjuvant cisplatin-irinotecan chemoradiation was tolerable; the OS appeared comparable to prior studies using neoadjuvant cisplatin-irinotecan chemoradiation alone ${ }^{44}$ The further mechanism of anticancer effects of COX-2 inhibitors should be elucidated, and results from large randomized clinical trials are needed to provide useful information in further establishing the efficacy of COX-2 inhibitors in adjuvant chemotherapy.

Our result was consistent with previous meta-analysis conducted by Li et al. ${ }^{45}$ In previous meta-analysis, they only focus on ESCC and their literature search time was closed on December 2008. Our meta-analysis included more studies and larger sample size to comprehensively evaluate the prognostic and clinicopathological significance of COX-2 expression in patients with EC (including ESCC and EADC). Various subgroup analyses (such as race, percentage of high COX-2 expression, histology type, treatment strategy, and sample size) were done; all these subgroup analyses suggested the significant association. However, in the study by Li et al, they did not conduct subgroup analysis. To some extent, with the larger sample size, comprehensive analysis, the reliability of our analysis was largely enhanced.

The significant heterogeneity was a major concern in our analysis. The significant heterogeneity was detected in our analysis. Although various subgroup analyses were conducted, we still could not find the source of heterogeneity. This may come from the different characteristics of the subjects in different studies. Furthermore, the methodology for IHC could affect the heterogeneity due to the various detecting antibodies against COX-2 and the application of different cutoff values for determining high COX-2 levels. 
Moreover, the HRs and their 95\% CIs we extracted from the OS data were not consistent. We have to estimate the HRs by reading the Kaplan-Meier curves because some studies did not report the HRs. For studies that reported the HRs, some provided the unadjusted HRs, whereas others provided the adjusted values. Even for adjusted HRs, the cofounders they adjusted in different studies were not the same. All of these factors more or less contributed to the heterogeneity.

At last, the potential publication bias may exist. Articles were not written in English and studies failed to get published because of negative or null results cannot be identified in our literature search, and thus were not included in this analysis. In addition, some reports that did not provide sufficient data were also excluded from our analysis.

\section{Conclusion}

Our study indicates that overexpression of COX-2 is correlated with tumor progression and prognosis of EC patients. COX-2 might be a predicative factor of progression and prognosis for patients with EC. With the limitations, heterogeneities, and bias of meta-analysis, our conclusions in this study need to be interpreted with caution. Future large prospective studies with rigorously designed methodology are warranted to confirm our results.

\section{Acknowledgment}

This work was supported by the key project of the National Natural Science Foundation (No U1202224).

\section{Disclosure}

The authors report no conflicts of interest in this work.

\section{References}

1. Brown LM, Devesa SS, Chow WH. Incidence of adenocarcinoma of the esophagus among white Americans by sex, stage, and age. J Natl Cancer Inst. 2008;100(16):1184-1187.

2. Lin Y, Totsuka Y, He Y, et al. Epidemiology of esophageal cancer in Japan and China. J Epidemiol. 2013;23(4):233-242.

3. Pennathur A, Gibson MK, Jobe BA, Luketich JD. Oesophageal carcinoma. Lancet. 2013;381(9864):400-412.

4. Dempke W, Rie C, Grothey A, Schmoll HJ. Cyclooxygenase-2: a novel target for cancer chemotherapy? J Cancer Res Clin Oncol. 2001;127(7): 411-417.

5. Rizzo MT. Cyclooxygenase-2 in oncogenesis. Clin Chim Acta. 2011; 412(9-10):671-687.

6. Takatori H, Natsugoe S, Okumura H, et al. Cyclooxygenase-2 expression is related to prognosis in patients with esophageal squamous cell carcinoma. Eur J Surg Oncol. 2008;34(4):397-402.

7. Prins MJ, Verhage RJ, ten Kate FJ, van Hillegersberg R. Cyclooxygenase isoenzyme-2 and vascular endothelial growth factor are associated with poor prognosis in esophageal adenocarcinoma. J Gastrointest Surg. 2012;16(5):956-966.

8. Bhandari P, Bateman AC, Mehta RL, et al. Prognostic significance of cyclooxygenase-2 (COX-2) expression in patients with surgically resectable adenocarcinoma of the oesophagus. BMC Cancer. 2006;6:134.
9. Nozoe T, Ezaki T, Kabashima A, Baba H, Maehara Y. Significance of immunohistochemical expression of cyclooxygenase-2 in squamous cell carcinoma of the esophagus. Am J Surg. 2005;189(1):110-115.

10. Okawa T, Naomoto Y, Nobuhisa T, et al. Heparanase is involved in angiogenesis in esophageal cancer through induction of cyclooxygenase-2. Clin Cancer Res. 2005;11(22):7995-8005.

11. Liu JF, Jamieson G, Wu TC, Zhang SW, Wang QZ, Drew P. Cyclooxygenase-2 expression in squamous cell carcinoma of the esophagus. Dis Esophagus. 2006;19(5):350-354.

12. Yoon MS, Nam TK, Lee JS, et al. VEGF as a predictor for response to definitive chemoradiotherapy and COX-2 as a prognosticator for survival in esophageal squamous cell carcinoma. J Korean Med Sci. 2011;26(4):513-520.

13. Hashimoto N, Inayama M, Fujishima M, Shiozaki H. Clinicopathologic significance of expression of cyclooxygenase-2 in human esophageal squamous cell carcinoma. Hepatogastroenterology. 2007;54(75): 758-760.

14. Buskens CJ, Van Rees BP, Sivula A, et al. Prognostic significance of elevated cyclooxygenase 2 expression in patients with adenocarcinoma of the esophagus. Gastroenterology. 2002;122(7):1800-1807.

15. Heeren P, Plukker J, van Dullemen H, Nap R, Hollema H. Prognostic role of cyclooxygenase-2 expression in esophageal carcinoma. Cancer Lett. 2005;225(2):283-289.

16. Huang JX, Chen WC, Lin M, et al. Clinicopathological significance of cyclooxygenase-2 and cell cycle-regulatory proteins expression in patients with esophageal squamous cell carcinoma. Dis Esophagus. 2012; 25(2):121-129.

17. France M, Drew PA, Dodd T, Watson DI. Cyclo-oxygenase-2 expression in esophageal adenocarcinoma as a determinant of clinical outcome following esophagectomy. Dis Esophagus. 2004;17(2): $136-140$.

18. Huang WZ, Fu JH, Wang DK, et al. Overexpression of cyclooxygenase-2 is associated with chemoradiotherapy resistance and prognosis in esophageal squamous cell carcinoma patients. Dis Esophagus. 2008; 21(8):679-684.

19. Liu WK, Jiang XY, Zhang MP, Zhang ZX. The relationship between HPV16 and expression of cyclooxygenase-2, P53 and their prognostic roles in esophageal squamous cell carcinoma. Eur $J$ Gastroenterol Hepatol. 2010;22(1):67-74.

20. Xi H, Baldus SE, Warnecke-Eberz U, et al. High cyclooxygenase-2 expression following neoadjuvant radiochemotherapy is associated with minor histopathologic response and poor prognosis in esophageal cancer. Clin Cancer Res. 2005;11(23):8341-8347.

21. Yang Z, Guan B, Men T, Fujimoto J, Xu X. Comparable molecular alterations in 4-nitroquinoline 1-oxide-induced oral and esophageal cancer in mice and in human esophageal cancer, associated with poor prognosis of patients. In Vivo. 2013;27(4):473-484.

22. Kawabe A, Shimada Y, Uchida S, et al. Expression of cyclooxygenase-2 is associated with carcinogenesis of the lower part of thoracic esophageal squamous cell carcinoma and p53 expression. Oncology. 2002;62(1):46-54.

23. Kuo KT, Chow KC, Wu YC, et al. Clinicopathologic significance of cyclooxygenase-2 overexpression in esophageal squamous cell carcinoma. Ann Thorac Surg. 2003;76(3):909-914.

24. Shamma A, Yamamoto H, Doki Y, et al. Up-regulation of cyclooxygenase-2 in squamous carcinogenesis of the esophagus. Clin Cancer Res. 2000;6(4):1229-1238.

25. Tierney JF, Stewart LA, Ghersi D, Burdett S, Sydes MR. Practical methods for incorporating summary time-to-event data into meta-analysis. Trials. 2007;8:16

26. Higgins JP, Thompson SG, Deeks JJ, Altman DG. Measuring inconsistency in meta-analyses. BMJ. 2003;327(7414):557-560.

27. Mantel N, Haenszel W. Statistical aspects of the analysis of data from retrospective studies of disease. J Natl Cancer Inst. 1959;22(4): 719-748.

28. DerSimonian R, Laird N. Meta-analysis in clinical trials. Control Clin Trials. 1986;7(3):177-188. 
29. Begg CB, Mazumdar M. Operating characteristics of a rank correlation test for publication bias. Biometrics. 1994;50(4):1088-1101.

30. Egger M, Davey Smith G, Schneider M, Minder C. Bias in meta-analysis detected by a simple, graphical test. BMJ. 1997;315(7109):629-634.

31. Kase S, Osaki M, Honjo S, et al. Expression of cyclooxygenase-1 and cyclooxygenase- 2 in human esophageal mucosa, dysplasia and carcinoma. Pathobiology. 2004;71(2):84-92.

32. Sivula A, Buskens CJ, van Rees BP, et al. Prognostic role of cyclooxygenase- 2 in neoadjuvant-treated patients with squamous cell carcinoma of the esophagus. Int J Cancer. 2005;116(6):903-908.

33. Yang GZ, Li L, Ding HY, Zhou JS. Cyclooxygenase- 2 is over-expressed in Chinese esophageal squamous cell carcinoma, and correlated with NF-kappaB: an immunohistochemical study. Exp Mol Pathol. 2005; 79(3):214-218.

34. Miyashita M, Makino H, Katsuta M, et al. Cyclo-oxygenase-2 overexpression is associated with human esophageal squamous cell carcinoma. J Nippon Med Sch. 2006;73(6):308-313.

35. Chen J, Wu F, Pei HL, et al. Analysis of the correlation between P53 and Cox-2 expression and prognosis in esophageal cancer. Oncol Lett. 2015;10(4):2197-2203.

36. Hu D, Zhang M, Wang S, Wang Z. High expression of cyclooxygenase 2 is an indicator of prognosis for patients with esophageal squamous cell carcinoma after Ivor Lewis esophagectomy. Thorac Cancer. 2016;7(3): 310-315.

37. Peng Q, Yang $\mathrm{S}$, Lao X, et al. Meta-analysis of the association between COX-2 polymorphisms and risk of colorectal cancer based on casecontrol studies. PLoS One. 2014;9(4):e94790.

38. Wang Z, He M, Xiao Z, Wu H, Wu Y. Quantitative assessment of the association of COX-2 (Cyclooxygenase-2) immunoexpression with prognosis in human osteosarcoma: a meta-analysis. PLoS One. 2013;8(12):e82907.
39. Grosch S, Maier TJ, Schiffmann S, Geisslinger G. Cyclooxygenase-2 (COX-2)-independent anticarcinogenic effects of selective COX-2 inhibitors. J Natl Cancer Inst. 2006;98(11):736-747.

40. Edelman MJ, Watson D, Wang X, et al. Eicosanoid modulation in advanced lung cancer: cyclooxygenase-2 expression is a positive predictive factor for celecoxib + chemotherapy - Cancer and Leukemia Group B Trial 30203. J Clin Oncol. 2008;26(6):848-855.

41. Antonarakis ES, Heath EI, Walczak JR, et al. Phase II, randomized, placebo-controlled trial of neoadjuvant celecoxib in men with clinically localized prostate cancer: evaluation of drug-specific biomarkers. J Clin Oncol. 2009;27(30):4986-4993.

42. Bundred NJ, Cramer A, Morris J, et al. Cyclooxygenase-2 inhibition does not improve the reduction in ductal carcinoma in situ proliferation with aromatase inhibitor therapy: results of the ERISAC randomized placebo-controlled trial. Clin Cancer Res. 2010;16(5):1605-1612.

43. Bastiaannet E, Sampieri K, Dekkers OM, et al. Use of aspirin postdiagnosis improves survival for colon cancer patients. Br J Cancer. 2012; 106(9):1564-1570.

44. Cleary JM, Mamon HJ, Szymonifka J, et al. Neoadjuvant irinotecan, cisplatin, and concurrent radiation therapy with celecoxib for patients with locally advanced esophageal cancer. BMC Cancer. 2016;16:468.

45. Li L, Zhao J, Wu Z, Wang G, Chen G. Meta-analysis: clinicopathological and prognostic significance of cyclooxygenase-2 expression on oesophageal squamous cell carcinoma. Aliment Pharmacol Ther. 2009; 30(6):589-596.
OncoTargets and Therapy

\section{Publish your work in this journal}

OncoTargets and Therapy is an international, peer-reviewed, open access journal focusing on the pathological basis of all cancers, potential targets for therapy and treatment protocols employed to improve the management of cancer patients. The journal also focuses on the impact of management programs and new therapeutic agents and protocols on

\section{Dovepress}

patient perspectives such as quality of life, adherence and satisfaction. The manuscript management system is completely online and includes a very quick and fair peer-review system, which is all easy to use. Visit http://www.dovepress.com/testimonials.php to read real quotes from published authors. 